\title{
Terrestrial Laser Scanning and Ground Truth Data for Characterizing Downed Dead Wood
}

\author{
Tuomas Yrttimaa ${ }^{1,2, *}$, Ninni Saarinen ${ }^{1,2}$, Ville Luoma ${ }^{2}$, Topi Tanhuanpää ${ }^{2,3}$, Ville \\ Kankare $^{1,2}$, Xinlian Liang ${ }^{4}$, Juha Hyyppä ${ }^{4}$, Markus Holopainen ${ }^{2,4}$ and Mikko Vastaranta \\ 1
}

${ }^{1}$ School of Forest Sciences, University of Eastern Finland, P.O. Box 111, 80101 Joensuu, Finland; ville.kankare@uef.fi (V.K.); mikko.vastaranta@uef.fi (M.V.)

${ }^{2}$ Department of Forest Sciences, University of Helsinki, P.O. Box 27, 00014 Helsinki, Finland; ninni.saarinen@uef.fi (N.S.); ville.luoma@helsinki.fi (V.L.); topi.tanhuanpaa@helsinki.fi (T.T.); markus.holopainen@helsinki.fi (M.H.)

${ }^{3}$ Department of Geographical and Historical Studies, University of Eastern Finland, P.O. Box 111, 80101 Joensuu, Finland

${ }^{4}$ Department of Remote Sensing and Photogrammetry, Finnish Geospatial Research Institute (National Land Survey of Finland), Geodeetinrinne 2, 02431 Masala, Finland; xinlian.liang@nls.fi (X.L.); juha.hyyppa@nls.fi (J.H.)

*Correspondence: tuomas.yrttimaa@uef.fi

\begin{abstract}
The feasibility of terrestrial laser scanning (TLS) in characterizing standing trees has been frequently investigated, while less effort has been put in quantifying downed dead wood using TLS. To advance dead wood characterization using TLS, we collected TLS point clouds and downed dead wood information from 20 sample plots (32 m x $32 \mathrm{~m}$ in size) located in southern Finland. This data set can be used in developing new algorithms for downed dead wood detection and characterization as well as for understanding spatial patterns of downed dead wood in boreal forests.
\end{abstract}

Data set: OSF repo https://osf.io/rjegd/

Data Set Licence: CC-By Attribution 4.0 International

Keywords: biodiversity, point cloud, coarse woody debris, algorithm

\section{Background and Summary}

Dead wood, in other words coarse woody debris (CWD) including standing dead trees (SDTs), downed woody debris (DWD) and stumps, is an important structural component in boreal forest ecosystems as it maintains the forest biodiversity and stores carbon tens of years after the tree death has occurred (Franklin et al. 1987; Krankina, Harmon 1995; Harmon, Sexton 1996; Esseen et al. 1997). Quantification of the CWD is most often based on field inventory (see Russell et al. 
2015) although complementary approaches using optical remote sensing (e.g. Bütler, Schlapfer 2004; Pasher, King 2009) as well as airborne laser scanning (Pesonen et al. 2008; Lindberg et al. 2013; Nyström et al. 2014; Tanhuanpää et al. 2015) have been introduced. During the last decade, the high potential of terrestrial laser scanning (TLS) to acquire dense point clouds for characterizing the forest structure has been noticed (Dassot et al. 2011; Newnham et al. 2015; Liang et al. 2016; Liang et al. 2018). TLS provides a detailed three-dimensional description of the scanner surroundings enabling versatile measurements from trees and tree groups. Development in scanner technology as well as advances in computational performance and data storing capacity have awakened the growing interest for the use of TLS-based approaches in forest inventory applications. The main interest behind the development of new TLS-based methods has been the utilization of dense terrestrial point clouds instead of or as a complement for conventional field inventory. In principle, TLS technology should be suitable for comprehensive description of forests, including topography, low vegetation and downed trees in addition to standing tree characteristics. However, the priority in studies regarding the use of TLS for forest characterization has been in the retrieval of attributes of live standing trees, while less effort has been put in characterizing other ecologically valuable structures such as CWD (Yrttimaa et al. 2019a).

Therefore, we collected data to develop a method for detecting and characterizing DWD using dense terrestrial point clouds from multi-scan TLS. In this data, DWD is defined as pieces of tree stems fallen on the forest floor because of an occurrence of a natural disturbance or harvesting, hereafter denoted as downed dead wood or dead wood trunks. From the TLS data, the dead wood trunks can be detected based on the geometric properties. Points representing the dead wood trunks can be classified and delineated for measuring trunk dimensions to derive the quantity and quality of downed dead wood on a sample plot. In the data, the quantity of dead wood is considered as the total volume of dead wood as well as the number of dead wood trunks in a sample plot. Dead wood quality is described as attributes related to trunk dimensions which are expected to be measurable from TLS data. In general, this data set can be used in developing new algorithms for downed dead wood detection and characterization as well as for understanding spatial patterns of downed dead wood in boreal forests. Automated methods are expected to speed up the processing and thus improving the applicability of TLS-based methods in dead wood inventory applications.

\section{Methods}

\section{Study area}

The study area is located in Evo, southern Finland, where the forests are dominated by Scots pine (Pinus sylvestris L.), Norway spruce (Picea abies (L.) H. Karst.) and birch (Betula L. sp). A mixture of managed and natural forests including both homogeneous and heterogeneous stands with varying growth stages are characterizing the forests in the area. In 2014, 91 sample plots (32 $\mathrm{m} \times 32 \mathrm{~m}$ in size) were established covering the structural variation of forests in the study area (for more details, see Yu et al. 2015, Vastaranta et al. 2018). 


\section{Selection of sample plots}

The sampling was based on visual interpretation of TLS point clouds collected 2014 from the 91 sample plots. For more details regarding the TLS data from 2014, see Yrttimaa et al. (2019b). Visual interpretation of the TLS point clouds was used because the field measurements from 2014 did not include downed dead wood information. A plot was included in the sub-sample if downed dead wood trunks were observed in the TLS point clouds from the sample plot. The number of sample plots for detection of downed dead wood. For more details, see Yrttimaa et al. (2019a).

\section{Terrestrial laser scanning data from the selected sample plots}

TLS data from the 20 sample plots were collected using Leica HDS6000 phase-shift scanner (Leica Geosystems, Heerbrugg, Switzerland) in leaf-off conditions in early November 2017. The scanning was conducted with high power settings providing a point cloud with point spacing 6.3 $\mathrm{mm}$ and point density approximately 25000 points $/ \mathrm{m}^{2}$ at a $10-\mathrm{m}$ distance from the scanner. The TLS data were collected the same way as in the year 2014 (Yrttimaa et al. 2019b), in other words, each sample plot was scanned using five static scanning positions, and the point clouds were combined using spherical reference targets attached to the trees with steel plates and magnets. The plates to which the reference targets were attached were not removed since the TLS campaign in 2014, so there was no need to re-define the exact locations of the targets. To facilitate the point cloud registration process, each reference target was equipped with a piece of white paper with the identification number in black on it. In this way, the reference targets could visually be identified from the point clouds coloured with laser intensity.

TLS data collection was followed by point cloud registration and filtering. The registration was conducted using Z + F LaserControl software (Zoller + Fröhlich GmbH, Wangen im Allgäu, Germany). First, the reference targets were visually detected and identified from a point cloud. Then, spherical objects equally sized to the reference targets were fitted to the points representing the reference targets in the point cloud. Using the fitted spherical objects, 3D-transformation between the point clouds (i.e. point cloud rotation and translation with respect to the centre plot scan) were calculated. As a result, the point clouds from each sample plot were combined with an accuracy of $1.7 \mathrm{~mm}$. In addition, a basic filtering procedure was utilized to remove noise from the point cloud. Depending on the forest structure, the number of points in a point cloud representing an entire sample plot varied between 104 million to 150 million.

\section{Reference measurements on downed dead wood}

Quantity and quality of downed dead wood was measured in the field during the TLS campaign in November 2017. All downed dead wood trunks with a diameter exceeding $5 \mathrm{~cm}$ at the middle of the trunk were measured in the field and considered as the field reference. For each trunk, tree species, bark coverage, and stage of decay were determined based on the field instructions for Finnish National Forest Inventory (Finnish Forest Research Institute 2009). The trunks were 
classified into five bark-cover-percentage classes based on ocular estimation. The stage of decay, on the other hand, was measured using a knife; the decay class was determined based on how much the blade penetrated the wood and more penetration indicated that the decaying process had proceeded further. Additionally, dimensions of the trunks were measured using a measuring tape and steel calipers. Length of each tree trunk and diameters along the trunks were measured. Diameters were measured at butt-end, at top-end, and at the middle of a trunk as well as at twometers intervals beginning from the butt-end of the trunk. Diameter at the middle of a trunk (i.e. mid-diameter) was also considered as one of the quality attributes. Trunk dimensions were then utilized to estimate the trunk volume. The volume was calculated using Huber formula (Equation 1) by dividing the trunk in sections and summing up the volume estimates of the trunk sections:

$$
V=\sum_{i=1}^{n} A_{m_{i}} l_{i}=\sum_{i=1}^{n} \frac{\pi l_{i}}{16}\left(d_{i}+d_{i+1}\right)^{2}
$$

where $A_{m_{i}}$ is the cross-sectional area measured in the middle of the $i^{\text {th }}$ trunk section, $l_{i}$ is the length of trunk section, $n$ is the total number of trunk sections, $d_{i}$ is the diameter measured at the buttend, and $d_{i+1}$ the diameter measured at the top-end of $i^{\text {th }}$ trunk section. According to the reference measurements, the total volume of downed dead wood in the 20 sample plots varied from 2.8 to $61.4 \mathrm{~m}^{3} /$ ha (Table 1). Highest volumes occurred on sample plots in old natural forests, while the lowest amounts of downed dead wood were observed in managed forests. Altogether, 304 dead wood trunks were measured in the field. Two thirds of the trunks were Norway spruce, while birches and Scots pine accounted for $19 \%$ and $10 \%$ of the trunks, respectively. Descriptive statistics from the field-measured downed dead wood trunk attributes as well as diameter distribution of the trunks are presented in detail in Table 2.

Table 1. Quality and quantity of downed dead wood in the 20 sample plots. $V=$ dead wood volume, $\mathrm{S}=$ number of measured dead wood trunks, decay-ratio $=$ ratio between the total volume of downed dead wood and the total volume of standing trees on the sample plot, $\mathrm{d}_{\mathrm{m}}=$ mean trunk middiameter, $1_{\mathrm{m}}=$ mean trunk length, $\mathrm{v}_{\mathrm{m}}=$ mean trunk volume.

\begin{tabular}{ccccccc}
\hline & $\mathrm{V}\left(\mathrm{m}^{3} / \mathrm{ha}\right)$ & $\mathrm{S}(\mathrm{n} / \mathrm{ha})$ & decay-ratio $(\%)$ & $\mathrm{d}_{\mathrm{m}}(\mathrm{cm})$ & $1_{\mathrm{m}}(\mathrm{m})$ & $\mathrm{v}_{\mathrm{m}}\left(\mathrm{dm}^{3}\right)$ \\
\hline $\min$ & 2.8 & 49 & 1.0 & 6.9 & 3.3 & 10.7 \\
mean & 25.3 & 150 & 7.4 & 14.3 & 7.6 & 192.6 \\
$\max$ & 61.4 & 479 & 25.3 & 21.0 & 11.6 & 460.3 \\
standard deviation & 18.6 & 97 & 5.8 & 3.8 & 2.2 & 127.8 \\
\hline
\end{tabular}


Table 2. Descriptive statistics of the field-measured downed dead wood trunks $(n=304)$. Middiameter stands for diameter measured at the middle of a trunk.

\begin{tabular}{|c|c|c|c|c|c|c|c|}
\hline & \multicolumn{3}{|c|}{ Mid-diameter $(\mathrm{cm})$} & \multicolumn{2}{|l|}{ Length (m) } & \multicolumn{2}{|l|}{ Volume $\left(\mathrm{dm}^{3}\right)$} \\
\hline $\min$ & & 5.0 & & 0.9 & & 3.4 & \\
\hline mean & & 13.3 & & 7.2 & & 170.5 & \\
\hline median & & 10.5 & & 5.9 & & 48.7 & \\
\hline $\max$ & & 39.5 & & 28.0 & & 2550.0 & \\
\hline $\begin{array}{l}\text { standard } \\
\text { deviation }\end{array}$ & & 7.7 & & 5.4 & & 316.8 & \\
\hline $\begin{array}{l}\text { mid-diameter } \\
\text { class }(\mathrm{cm})\end{array}$ & $5-10$ & $10-15$ & $15-20$ & $20-25$ & $25-30$ & $30-35$ & $35-40$ \\
\hline $\mathrm{n}$ & 142 & 71 & 33 & 29 & 13 & 12 & 4 \\
\hline $\begin{array}{l}\text { proportion of } \\
\text { trunks }(\%)\end{array}$ & 46.7 & 23.4 & 10.9 & 9.5 & 4.3 & 3.9 & 1.3 \\
\hline $\begin{array}{l}\text { proportion of } \\
\text { volume }(\%)\end{array}$ & 7.0 & 13.1 & 12.5 & 24.7 & 17.2 & 21.7 & 3.8 \\
\hline
\end{tabular}

\section{Data Records}

This data set includes one file ("dead_wood.zip") that can be downloaded from https://osf.io/rjegd/. The dead_wood.zip includes dead_wood_attributes.txt, which includes dead wood characteristics for each of the 20 sample plots. Dead_wood_attributes.txt has the following columns: Sample plot ID, V, S, decay-ratio, $\mathrm{d}_{\mathrm{m}}, \mathrm{l}_{\mathrm{m}}, \mathrm{v}_{\mathrm{m}}$. The used units and definitions are as presented in Table 1. Additionally, dead_wood.zip also includes 20 .laz-files including sample plot ID in the filename (e.g. sample_plot_19.1az). The laz-files include normalized TLS point clouds below $1.0 \mathrm{~m}$ above the ground level and in a local coordinate system (units are in meters). Normalization was done using LAStools software (Isenburg 2019). It should be noted that raw point clouds were voxelized with $0.5 \mathrm{~cm}$ resolution.

\section{Technical Validation}

At the sample plot level, TLS point clouds were co-registered with an average registration accuracy of $1.7 \mathrm{~mm}$ (Yrttimaa et al. 2019a) indicating high geometric accuracy of the point clouds. When similarly collected point clouds have been used to automatically measure tree diameters at multiple heights along a stem, root mean square error less than $1 \mathrm{~cm}$ can be expected in boreal forest conditions (Saarinen et al. 2017, Liang et al. 2018). In this data, calipers were used for dead wood diameter measurements with an expected precision of $0.3 \mathrm{~cm}$ (Luoma et al. 2017).

\section{Acknowledgements}


The authors would like to thank the personnel at the Evo campus of Häme University of Applied Sciences for supporting our research activities at the study site.

\section{Author Contributions}

Conceptualization, T.Y. M.V., N.S., T.T.; data curation, T.Y., V.L. and X.L.; data processing, T.Y., V.K.; funding and supervision, J.H., M.H., M.V.; writing — original draft preparation, T.Y, N.S., M.V.; writing — review and editing, all the authors.

\section{Conflicts of Interest}

The authors declare no conflict of interest.

\section{References}

Esseen, P.-A., Ehnström, B., Ericson, L., Sjöberg, K., 1997. Boreal forests. Ecological Bulletins $46,16-47$.

Bütler, R., Schlaepfer, R., 2004. Spruce snag quantification by coupling colour infrared aerial photos and a GIS. Forest Ecology and Management, 195(3), 325-339.

Dassot, M., Constant, T., Fournier, M., 2011. The use of terrestrial LiDAR technology in forest science: application fields, benefits and challenges. Annals of forest science, 68(5), 959-974.

Finnish Forest Research Institute, 2009. Valtakunnan metsien 11. inventointi (VMI11) maastotyön ohjeet 2009 Koko Suomi, 2. painos. (In Finnish).

Franklin, J.F., Shugart, H.H., Harmon, M.E., 1987. Tree death as an ecological process. BioScience 37, 550-556.

Harmon, M.E., Sexton, J., 1996. Guidelines for Measurements of Woody Debris in Forest Ecosystems. Pub. No. 20. US LTER Network Office, Univ. of Washington, Seattle, WA. 73 pp.

Isenburg, M. 2019. LAStools-Efficient LiDAR Processing Software, (version 181001 academic); rapidlasso GmbH: Gilching, Germany. http://rapidlasso.com/LAStools

Krankina, O.N., Harmon, M.E., 1995. Dynamics of the dead wood carbon pool in northwestern Russian boreal forests. Water, Air, and Soil Pollution, 82(1-2), 227-238.

Liang, X., Kankare, V., Hyyppä, J., Wang, Y., Kukko, A., Haggrén, H., Yu, X., Kaartinen, H., Jaakkola, A., Guang, F., Holopainen, M., Vastaranta, M., 2016. Terrestrial laser scanning in forest inventories. ISPRS Journal of Photogrammetry and Remote Sensing 115, 63-77.

Liang, X., Hyyppä, J., Kaartinen, H., Lehtomäki, M., Pyörälä, J., Pfeifer, N., Holopainen, M., Brolly, G., Francesco, P., Hackenberg, J., Huang, H., 2018. International benchmarking of terrestrial laser scanning approaches for forest inventories. ISPRS Journal of Photogrammetry and Remote Sensing, 144, 137-179. 
Lindberg, E., Hollaus, M., Mücke, W., Fransson, J. E., Pfeifer, N., 2013. Detection of lying tree stems from airborne laser scanning data using a line template matching algorithm. ISPRS Annals of Photogrammetry, Remote Sensing and Spatial Information Sciences 5, 169-174.

Luoma, V., Saarinen, N., Wulder, M.A., White, J.C., Vastaranta, M., Holopainen, M., Hyyppä, J. Assessing precision in conventional field measurements of individual tree attributes. Forests $2017,8,38$.

Newnham, G.J., Armston, J.D., Calders, K., Disney, M.I., Lovell, J.L., Schaaf, C.B., Strahler, A.H., Danson, F.M., 2015. Terrestrial laser scanning for plot-scale forest measurement. Current Forestry Reports, 1(4), 239-251.

Nyström, M., Holmgren, J., Fransson, J.E.S., Olsson, H., 2014. Detection of windthrown trees using airborne laser scanning. International Journal of Applied Earth Observation and Geoinformation 30, 21-29.

Pasher, J., King, D.J., 2009. Mapping dead wood distribution in a temperate hardwood forest using high resolution airborne imagery. Forest Ecology and Management, 258(7), 1536-1548.

Pesonen, A., Maltamo, M., Eerikäinen, K., Packalèn, P., 2008. Airborne laser scanning-based prediction of coarse woody debris volumes in a conservation area. Forest Ecology and Management, 255(8-9), 3288-3296.

Russell, M.B., Fraver, S., Aakala, T., Gove, J.H., Woodall, C.W., D’Amato, A.W., Ducey, M.J., 2015. Quantifying carbon stores and decomposition in dead wood: A review. Forest Ecology and Management, 350, 107-128.

Saarinen, N., Kankare, V., Vastaranta, M., Luoma, V., Pyörälä, J., Tanhuanpää, T., Liang, X., Kaartinen, H., Kukko, A., Jaakkola, A., Yu, X., 2017. Feasibility of Terrestrial laser scanning for collecting stem volume information from single trees. ISPRS Journal of Photogrammetry and Remote Sensing, 123, pp.140-158.

Tanhuanpää, T., Kankare, V., Vastaranta, M., Saarinen, N., Holopainen, M., 2015. Monitoring downed coarse woody debris through appearance of canopy gaps in urban boreal forests with bitemporal ALS data. Urban Forestry \& Urban Greening 14 (4), 835-843.

Vastaranta, M., Yrttimaa, T., Saarinen, N., Yu, X., Karjalainen, M., Nurminen, K., Karila, K., Kankare, V., Luoma, V., Pyörälä, J., Junttila, S., et al., 2018. Airborne laser scanning outperforms the alternative 3D techniques in capturing variation in tree height and forest density in southern boreal forests. Baltic Forestry, 24(2), pp.268-277

Yrttimaa, T., Saarinen, N., Luoma, V., Tanhuanpää, T., Kankare, V., Liang, X., Hyyppä, J., Holopainen, M., Vastaranta, M., 2019a. Detecting and characterizing downed dead wood using terrestrial laser scanning. ISPRS journal of photogrammetry and remote sensing, 151, pp.7690. 
Yrttimaa, T., Saarinen, N., Kankare, V., Liang, X., Hyyppä, J., Holopainen, M., Vastaranta, M., 2019b. Investigating the Feasibility of Multi-Scan Terrestrial Laser Scanning to Characterize Tree Communities in Southern Boreal Forests. Remote Sensing, 11(12), p.1423.

Yu, X., Hyyppä, J., Karjalainen, M., Nurminen, K., Karila, K., Vastaranta, M., Kankare, V., Kaartinen, H., Holopainen, M., Honkavaara, E., Kukko, A., Jaakkola, A., Liang, X., Wang, Y., Hyyppä, H., Katoh, M., 2015. Comparison of Laser and Stereo Optical, SAR and InSAR Point Clouds from Air- and Space-Borne Sources in the Retrieval of Forest Inventory Attributes. Remote Sensing 2015(7), 15933-15954. 